\title{
STUDY OF MOLECULAR SURFACE PROPERTY OF PHOSPHOLIPASE A2 (PLA2) FROM NAJA NAJA
}

\author{
Gomase V.S.*, Gangawane A.K. and More A.R. \\ *Department of Bioinformatics, Padmashree Dr. D.Y. Patil University, Navi Mumbai, 400614, India, Mobile- \\ +91-9987770696, Mail-virusgene1@yahoo.co.in
}

\begin{abstract}
This study was designed to elucidate the signalling pathways by which secretary phospholipase a2 (sPLA2s) induce in vitro neutrophil migration and PLA2 inhibits platelet aggregation in PRP and explains the decreased clot retraction and retarded and compromised elasticity build up. Naja naja venoms are complex and contain several toxic components, including neurotoxins and phospholipases A2 that cause post-synaptic neuromuscular blockade with respiratory paralysis and cardiac arrest. The antigenic epitopes on phospholipase a2 (Pla2) are important determinant of protection against venom. In this analysis, we found the antigenic epitopes 29-GRGGSGTPVDD-39, 77-TCKGDNNACA-86, of protein called the antigenic determinant or the epitope is sufficient for eliciting the desired immune response. Also predict the MHC binder and these MHC Class peptide segments are from a set of aligned peptides known to bind to a given major histocompatibility complex (MHC) molecule as the predictor of MHC-peptide binding. Binding ability prediction of antigen peptides to MHC class molecules is important in vaccine development. The method integrates prediction of peptide $\mathrm{MHC}$ class binding; proteasomal $\mathrm{C}$ terminal cleavage efficiency of protein.

Keywords- phospholipases a2, epitope, hydrophobicity, MHC, surface activity, SVM, PSSM, peptide vaccine

Abbreviations: Major Histocompatibility Complex, (MHC); Position Specific Scoring Matrices, (PSSMs); Support Vector Machine, (SVM)
\end{abstract}

${ }^{*}$ Correspondence: Dr. Virendra S. Gomase, Department of Bioinformatics, Padmashree Dr. D.Y. Patil University, Plot No-50, Sector-15, CBD Belapur, Navi Mumbai, 400614, India; Mobile- +91-9987770696; Mail- virusgene1@yahoo.co.in

\section{Introduction}

Venomous animals contain concentrates of biologically active substances developed to block vital physiological and biochemical functions of the victims. This has contrasting human health concerns, provide important pharmacological raw material and pose a serious threat to human life and health in tropical and subtropical regions ${ }^{1}$. Phospholipase A2 (PLA2) is the superfamily consists of many different groups of enzymes that catalyze the hydrolysis of the sn-2 ester bond in a variety of different phospholipids. This reaction produces a free fatty acid and lysophospholipid have many different important physiological roles ${ }^{2}$. Phospholipase A2 (PLA2) enzymes from snake venom are toxic and induce a wide spectrum of pharmacological effects, also similarity in primary, secondary and tertiary structures and common catalytic properties. The structure-function relationships and the mechanism of this group of small proteins are subtle, complex and intriguing challenges. It is strongly anticoagulant CM-IV binding properties to factor $\mathrm{Xa}$ (its target protein) through the specific anticoagulant site on its surface. In contrast, weakly anticoagulant enzymes, which lack the anticoagulant region fail to bind specifically to the target protein, factor $\mathrm{Xa}$ in the coagulation cascade. Our research studies strongly define the target model, which suggests protein-protein interaction rather than proteinphospholipid interaction determines the pharmacological specificity of PLA2 enzymes ${ }^{3,4}$. Peptide fragments from Phospholipase A2 involved multiple antigenic components directing and empowering the immune system to protect the host from infection. MHC molecules are cell surface proteins, which take active part in host immune reactions and involvement of $\mathrm{MHC}$ class-I \& II in response to almost all antigens. So a small fragment of antigen can induce immune response against whole antigen. This theme is implemented in designing subunit and synthetic peptide vaccines. The sequence analysis method allows potential drug targets to identify active sites against diseases. The method integrates prediction of peptide MHC class binding affinity, hydrophobicity and relative flexibility of given protein molecule ${ }^{5,6}$.

\section{Methodology}

In this research work antigenic epitopes of phospholipase A2 protein from Naja naja is determined using the Gomase in 2007, Hopp and Woods, Welling, Parker and Protrusion Index (Thornton) antigenicity ${ }^{7-9}$. The major histocompatibility complex (MHC) peptide binding of phospholipase A2 protein is predicted using neural networks trained on $C$ terminals of known epitopes. In analysis predicted MHC/peptide binding of phospholipase A2 protein is a logtransformed value related to the IC50 values in $\mathrm{nM}$ units. MHC2Pred predicts peptide binders to $\mathrm{MHCl}$ and $\mathrm{MHCll}$ molecules from protein 
sequences or sequence alignments using Position Specific Scoring Matrices (PSSMs). Support Vector Machine (SVM) based method for prediction of promiscuous MHC class II binding peptides. SVM has been trained on the binary input of single amino acid sequence ${ }^{10-15}$. In addition, we predict those MHC ligands from whose C-terminal end is likely to be the result of proteosomal cleavage ${ }^{16,17}$.

\section{Results and Interpretations}

We found binding of peptides to a number of different alleles using Position Specific Scoring Matrix. A phospholipase A2 protein sequence is 119 residues long, having antigenic $\mathrm{MHC}$ binding peptides. MHC molecules are cell surface glycoproteins, which take active part in host immune reactions and involvement of $\mathrm{MHC}$ class-I and MHC II in response to almost all antigens (Fig. 7). PSSM based server predict the peptide binders to $\mathrm{MHCl}$ molecules of phospholipase A2 protein sequence are as 11mer_H2_Db, 10mer_H2_Db, 9mer_H2_Db, 8mer_ ${ }^{2} 2$ Db and also peptide binders to $\mathrm{MHCll}$ molecules of phospholipase A2 protein sequence as I_Ab.p, I_Ad.p, analysis found antigenic epitopes region in putative phospholipase A2 protein (Table 1). We also found the SVM based MHCII-IAb peptide regions; MHCII-IAd peptide regions; MHCII-IAg7 peptide regions and MHCII- RT1.B peptide regions, which represented predicted binders from phospholipase A2 protein (Table 2). The predicted binding affinity is normalized by the $1 \%$ fractil. We describe an improved method for predicting linear epitopes (Table 2). The region of maximal hydrophilicity is likely to be an antigenic site, having hydrophobic characteristics, because terminal regions of phospholipase A2 protein is solvent accessible and unstructured, antibodies against those regions are also likely to recognize the native protein (Fig. 1, 2, 5, 6). It was shown that a phospholipase A2 protein is hydrophobic in nature and contains segments of low complexity and high-predicted flexibility (Fig. 3, 4). Predicted antigenic fragments can bind to $\mathrm{MHC}$ molecule is the first bottlenecks in vaccine design.

\section{Conclusion}

A phospholipase A2 protein from Naja naja peptide nonamers are from a set of aligned peptides known to bind to a given $\mathrm{MHC}$ molecule as the predictor of $\mathrm{MHC}$-peptide binding. MHCII molecules bind peptides in similar yet different modes and alignments of $\mathrm{MHCll}$-ligands were obtained to be consistent with the binding mode of the peptides to their $\mathrm{MHC}$ class, this means the increase in affinity of $\mathrm{MHC}$ binding peptides may result in enhancement of immunogenicity of phospholipase A2 protein. These predicted of phospholipase A2 protein antigenic peptides to $\mathrm{MHC}$ class molecules are important in vaccine development from Naja naja.

\section{References}

1 Gazarian KG, Gazarian T, Hernández R, Possani LD (2005) Vaccine 23(26), 3357-68.

2 Burke JE, Dennis EA. (2009) Cardiovasc Drugs Ther 23(1), 49-59.

3 Kini RM (2005) Toxicon 45(8), 1147-61.

4 Stefansson S, Kini RM, Evans HJ (1989) Thromb Res 55(4), 481-91.

5 Gomase VS, Kale KV, Chikhale NJ, Changbhale SS (2007) Curr Drug Discov Technol 4(2), 117-215.

6 Gomase VS (2006) Curr Drug Discov Technol3(3), 225-9.

7 Gomase VS, Kale KV and Shyamkumar K (2008) J. of Proteomics \& Bioinformatics, 1 (4), 188- 205.

8 Gomase VS, Waghmare SB, Jadhav BV, Kale KV (2009 Gene Therapy and Mol. Bio. 13, 11-15.

9 Gomase VS, Kale KV (2008) Int. J. of Applied Computing, 1(1), 39-46.

10 Gomase VS (2008) Int. J. of Bioinformatics, 1(1), 47-51.

11 Gomase VS, Kale KV (2008) Int. J. of Information Retrieval, 1(1), 11-15.

12 Gomase VS, Kale KV, Shyamkumar K and Shankar S. ICETET 2008, IEEE Computer Society in IEEE Xplore, Los Alamitos, California, 629-634, 2008.

13 Gomase VS, Tandale JP, Patil SA, Kale KV. 14th International Conference on Advance Computing \& Communication, Published by IEEE Computer Society in IEEE Xplore USA 614-615, 2006.

14 Reche PA, Glutting JP, Reinherz EL, (2002) Hum Immun., 63, 701-709.

15 Buus S, Lauemøller SL, Worning P, Kesmir C, Frimurer T, Corbet S, Fomsgaard A, Hilden J, Holm A, Brunak S (2003) Tissue Antigens 62 (5), 378-384.

16 Nielsen $M$, Lundegaard $C$, Worning $P$, Lauemøller SL, Lamberth K, Buus S, Brunak S, Lund O (2003) Protein Sci., 12, 1007-1017.

17 Bhasin M and Raghava GP (2005) Nucleic Acids Research, 33, W202-207. 
Table 1- PSSM based prediction of MHC ligands, from whose C-terminal ends are proteosomal cleavage sites

\begin{tabular}{|l|l|l|l|l|l|l|l|}
\hline MHC-I & POS. & N & Sequence & C & MW (Da) & Score & $\%$ OPT. \\
\hline 9mer_H2_Db & 107 & PYN & DNNYNIDLK & ARC & 1090.15 & 13.298 & $26.40 \%$ \\
\hline 9mer_H2_Db & 102 & CFA & GAPYNDNNY & NID & 1009.0 & 12.554 & $24.93 \%$ \\
\hline 10mer_H2_Db & 48 & QVH & DNCYNEAEKI & SGC & 1180.26 & 22.756 & $38.66 \%$ \\
\hline 10mer_H2_Db & 58 & EKI & SGCWPYFKTY & SYE & 1210.41 & 15.882 & $26.98 \%$ \\
\hline 11merH2_Db & 95 & CDR & LAAICFAGAPY & NDN & 1078.31 & 15.928 & $20.04 \%$ \\
\hline 11mer_H2_Db & 90 & ASV & CDCDRLAAICF & AGA & 1211.45 & 13.598 & $17.11 \%$ \\
\hline
\end{tabular}

Table 2- SVM based prediction of MHC class II binding peptides from phospholipase A2 protein

\begin{tabular}{|l|l|l|l|l|}
\hline $\begin{array}{l}\text { MHC } \\
\text { ALLELE }\end{array}$ & Rank & Sequence & $\begin{array}{l}\text { Residue } \\
\text { No. }\end{array}$ & $\begin{array}{l}\text { Peptide } \\
\text { Score }\end{array}$ \\
\hline I-Ab & 1 & GTPVDDLDR & 34 & 0.749 \\
\hline I-Ab & 2 & GAPYNDNNY & 102 & 0.597 \\
\hline I-Ab & 3 & PYFKTYSYE & 62 & 0.518 \\
\hline I-Ab & 4 & IKCTVPSRS & 9 & 0.464 \\
\hline I-Ad & 1 & ADYGCYCGR & 22 & 0.524 \\
\hline I-Ad & 2 & LDRCCQVHD & 40 & 0.519 \\
\hline I-Ad & 3 & CYCGRGGSG & 26 & 0.468 \\
\hline I-Ad & 4 & GRGGSGTPV & 29 & 0.455 \\
\hline I-Ag7 & 1 & GDNNACAAS & 80 & 1.741 \\
\hline I-Ag7 & 2 & WDFADYGCY & 19 & 1.517 \\
\hline I-Ag7 & 3 & YGCYCGRGG & 24 & 1.432 \\
\hline I-Ag7 & 4 & KGDNNACAA & 79 & 1.418 \\
\hline RT1.B & 1 & KTYSYECSQ & 65 & 0.722 \\
\hline RT1.B & 2 & SYECSQGTL & 68 & 0.547 \\
\hline RT1.B & 3 & NNACAASVC & 82 & 0.419 \\
\hline RT1.B & 4 & YECSQGTLT & 69 & 0.403 \\
\hline
\end{tabular}




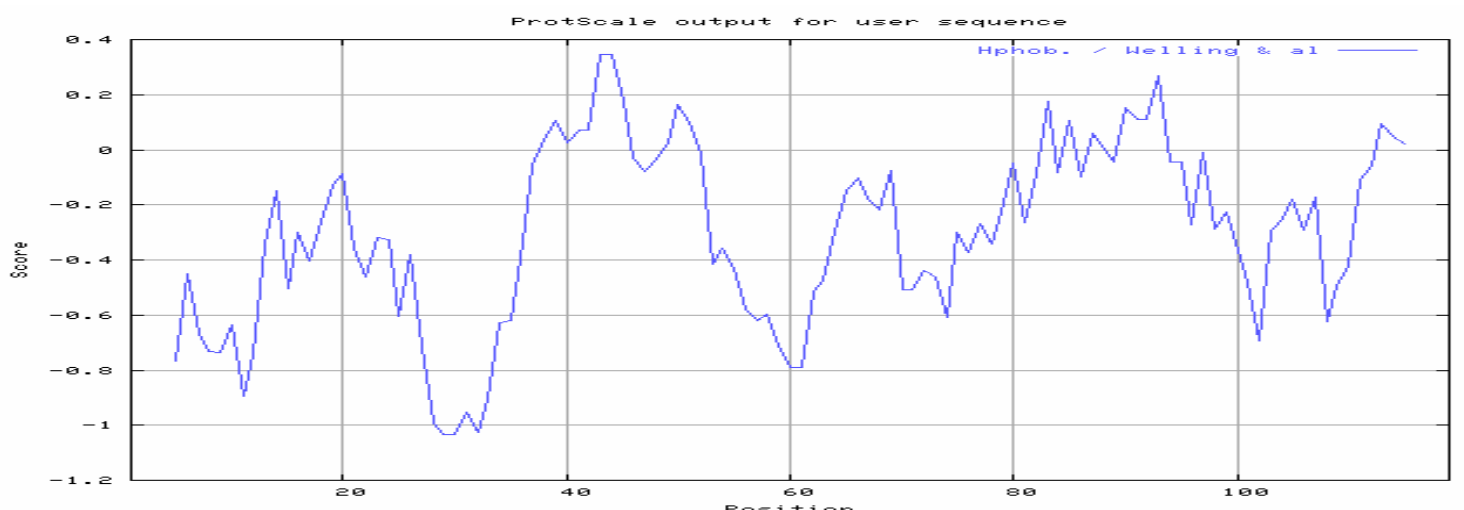

Fig. 1- Antigenicity plot of phospholipase A2 protein by Welling, et al., scale

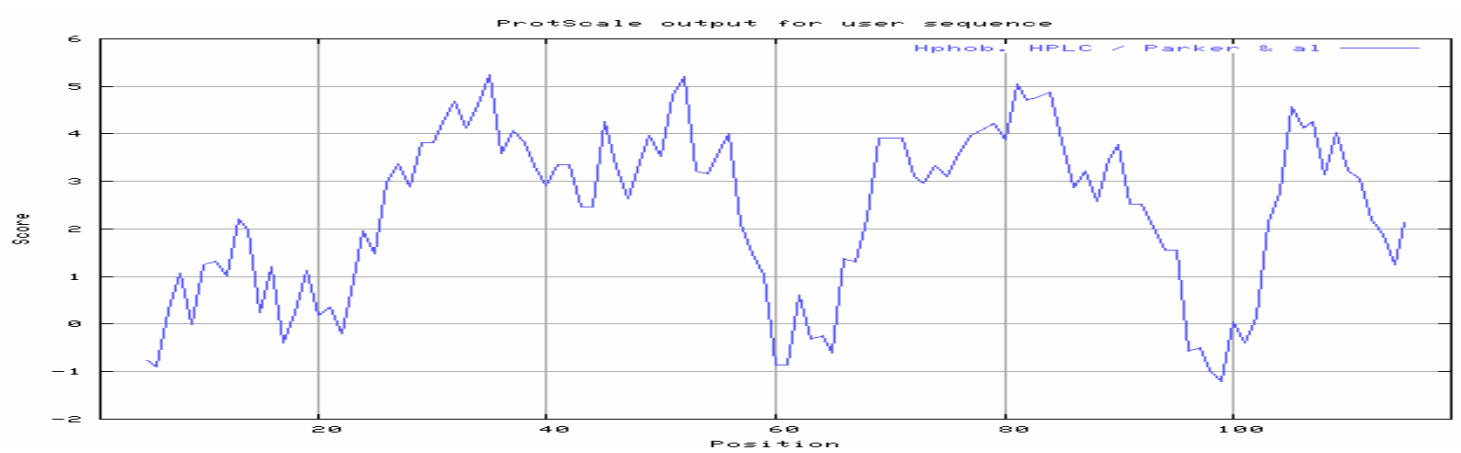

Fig. 2- Antigenicity plot of phospholipase A2 protein by HPLC / Parker, et al., scale

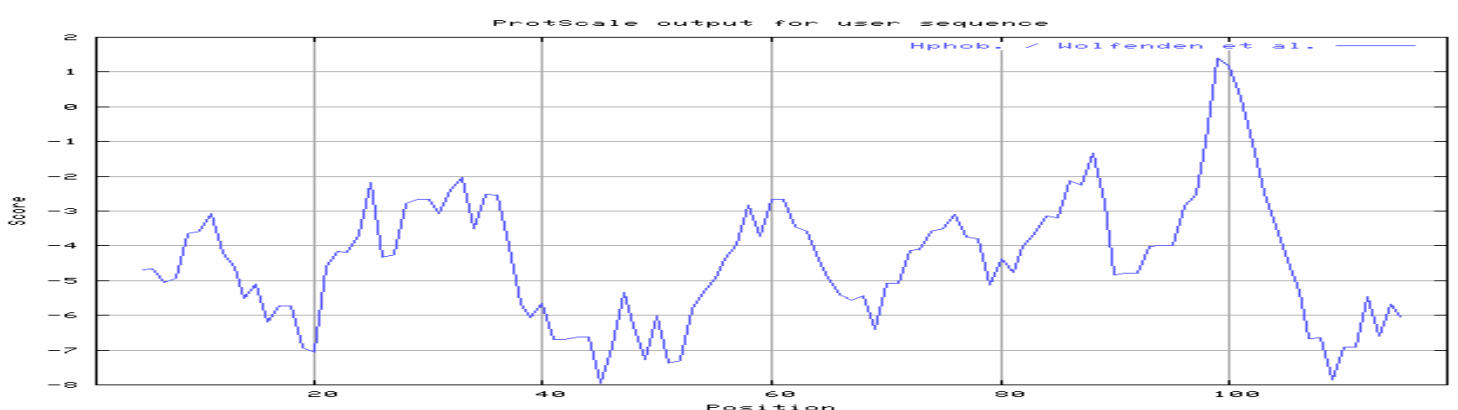

Fig. 3- Hydrophobicity plot of phospholipase A2 protein by Wolfenden, et al., scale

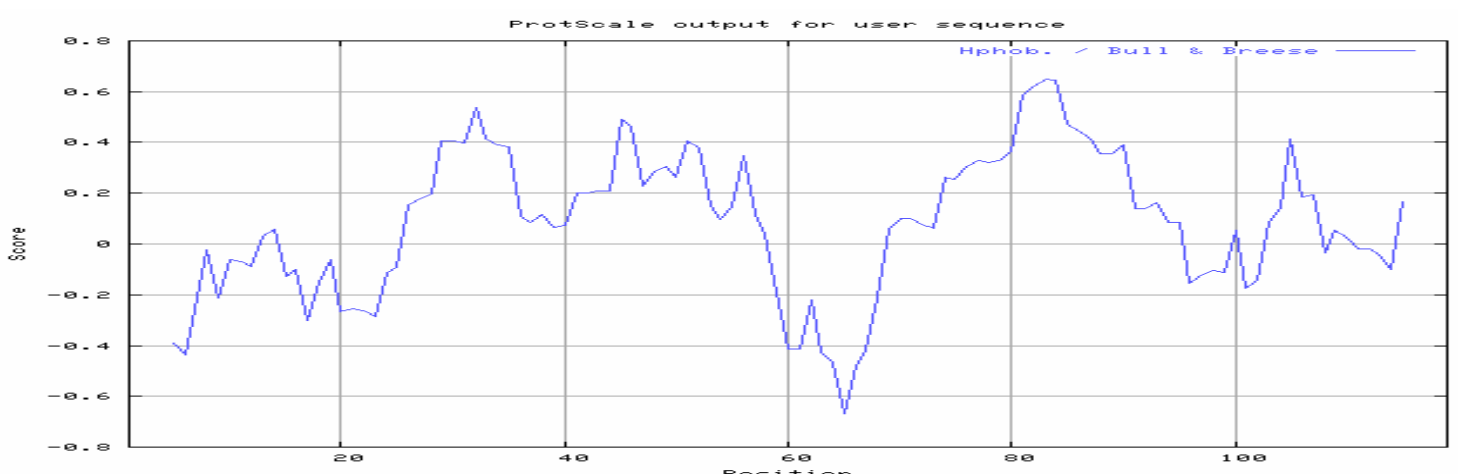

Fig. 4-Hydrophobicity plot of phospholipase A2 protein by Bull \& Breese scale 


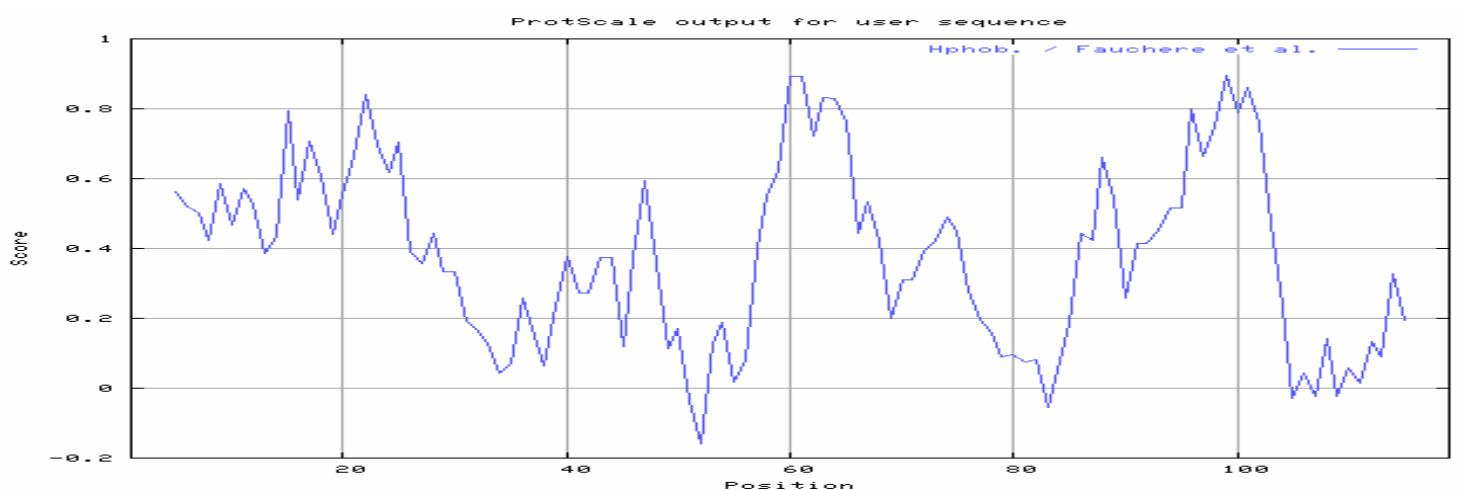

Fig. 5-Hydrophobicity plot of phospholipase A2 protein by Fauchere et al., scale

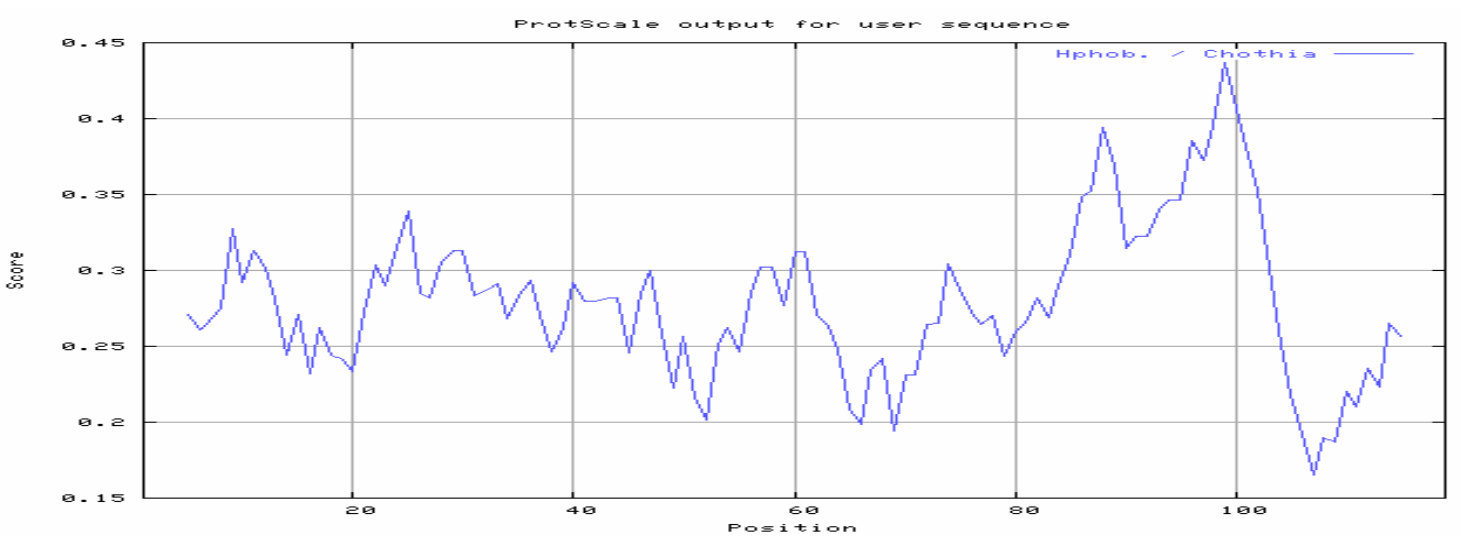

Fig. 6-Hydrophobicity plot of phospholipase A2 protein by Chothia scale

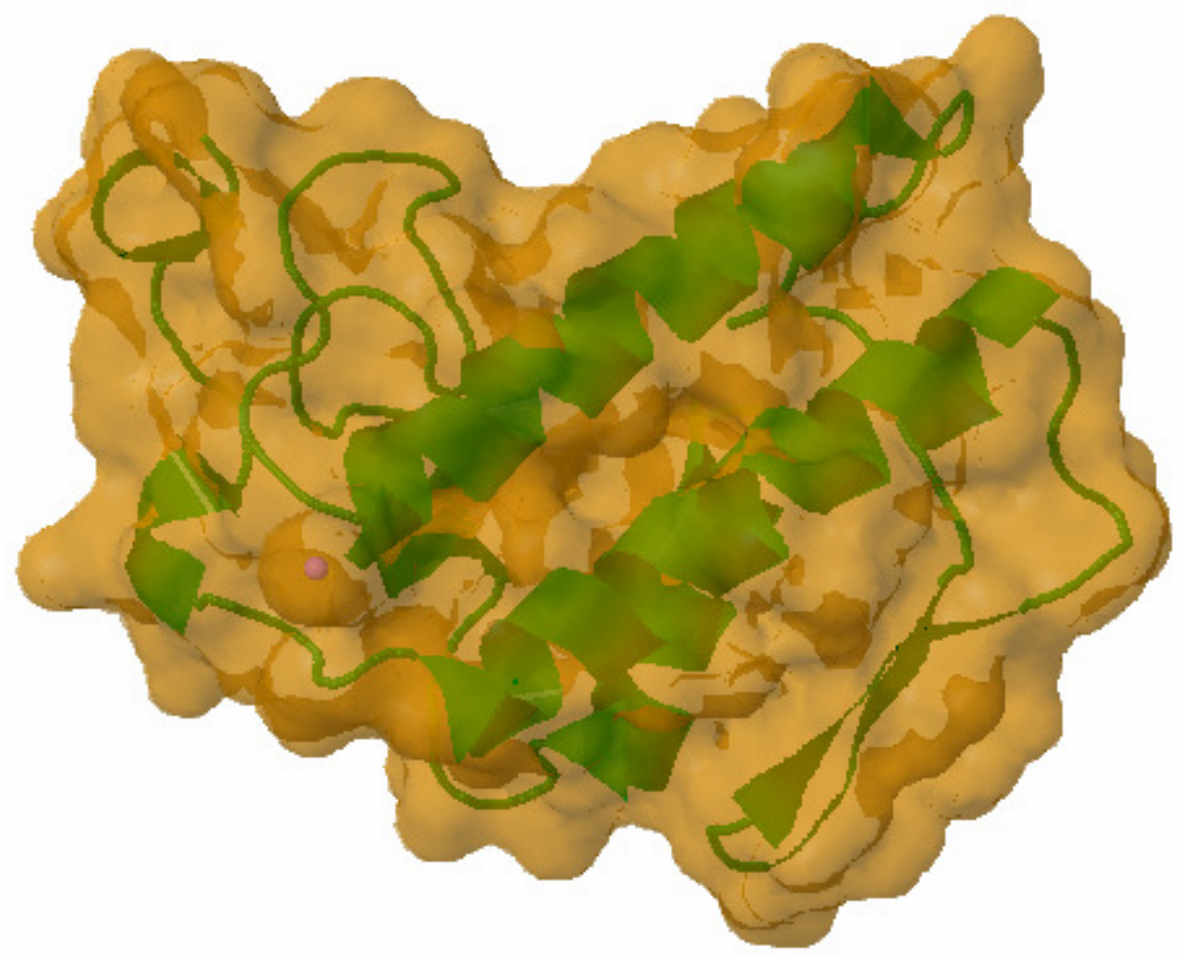

Fig. 7- Phospholipase A2 protein structure of $1 A 3 D$ 